\title{
PERANCANGAN TAMPILAN USER INTERFACE PADA WEBSITE KLINIK SEHAT BERDASARKAN METODE PAPER PROTOTYPE
}

\section{DESIGN OF USER INTERFACE ON THE HEALTHY CLINIC WEBSITE BASED ON THE PAPER PROTOTYPE METHOD}

\author{
Hendy Tannady ${ }^{1^{*}}$, Dela Haeraini ${ }^{2}$, Dina Natalia ${ }^{3)}$ \\ ${ }^{1)}$ Program Studi Magister Manajemen, Institut Teknologi dan Bisnis Kalbis, Jakarta \\ 2,3,) Program Studi Sistem Informasi, Universitas Bunda Mulia, Jakarta
}

Diterima 12 Juli 2021 / Disetujui 20 Juli 2021

\begin{abstract}
The role of information technology for companies has an important role and can be the center of business strategy to gain competitive advantage. Currently, information technology has become a basic need for every company. Companies that want to be widely known as well as companies that want to maintain relationships with their customers need to create a website/website that contains company profile information and the services/products provided. Every website must have a different user interface. Healthy Clinics are the same as clinics in general which provide effective and efficient services. To improve clinical services, the clinic wants to create a website that users can use to easily see ongoing activities at the clinic. By creating a clinic website, the interface plays an important role in making the website. The interface is the first thing that is seen when the user opens the Health Clinic website. The interface is the benchmark. To create a user-friendly interface, the Kinik party made an interface using the paper prototype method. Paper prototypes can help create an interface at the beginning of its development. The results obtained in this paper are the paper prototype method suitable for use to create a user interface display on websites such as the Healthy Clinic, a user-friendly user interface for website users, Users can test the interface with real actions and can also determine own actions or tasks that can be understood and performed when using the application/website intuitively.
\end{abstract}

Keywords: website, interface, paper prototype

\begin{abstract}
ABSTRAK
Peran teknologi informasi bagi perusahaan mempunyai peranan penting dan dapat menjadi pusat strategi bisnis untuk memperoleh keunggulan bersaing. Saat ini teknologi informasi sudah menjadi kebutuhan dasar bagi setiap perusahaan. Perusahaan yang ingin dikenal secara luas maupun perusahaan yang ingin menjaga hubungan dengan pelanggannya perlu membuat situs/website yang berisi informasi profil perusahaan maupun jasa/produk yang diberikan. Setiap website pasti memiliki sebuah user interface yang berbeda-beda. Klinik Sehat sama seperti klinik pada umumnya yang memberikan pelayanan yang efektif dan efisien. Untuk meningkatkan pelayanan klinik, pihak klinik ingin membuat website yang dapat digunakan pengguna untuk mudah melihat aktifitas yang sedang berlangsung di klinik. Dengan membuat website klinik, tampilan antarmuka (interface) berperan penting dalam pembuatan website. Interface merupakan hal yang di lihat pertama kali pada saat pengguna membuka website Klinik Sehat. Interface menjadi patokan. Untuk membuat interface yang bersifat user friendly pihak kinik membuat interface dengan metode paper prototype. Paper prototype dapat membantu membuat interface pada awal pengembangannya. Hasil yang di dapat pada paper ini adalah metode paper prototype cocok digunakan untuk membuat tampilan user interface pada website seperti Klinik Sehat, tampilan user interface yang user friendly bagi para pengguna website, Pengguna dapat melakukan ujicoba antarmuka dengan aksi-aksi yang nyata dan juga dapat menentukan sendiri aksi atau tugas apa saja yang bisa dipahami dan dilakukan ketika menggunakan aplikasi/website tersebut secara intuitif.
\end{abstract}

Kata Kunci: website, interface, paper prototype

*Korespondensi Penulis :

Email : hendytannady@kalbis.ac.id 


\section{PENDAHULUAN}

Pembuatan user interface bertujuan untuk menjadikan teknologi informasi tersebut mudah digunakan oleh pengguna atau disebut dengan istilah user friendly. Istilah user friendly digunakan untuk menunjuk kepada kemampuan yang dimiliki oleh perangkat lunak atau program aplikasi yang mudah dioperasikan, dan mempunyai sejumlah kemampuan lain sehingga pengguna merasa betah dalam mengoperasikan program tersebut (Alfian, dkk., 2004).

Perkembangan website telah mengarah pada perusahaan dan organisasi dengan memindahkan banyak upaya bisnis mereka ke lingkungan online (Awais dan Samin, 2012), (Andry, dkk, 2020). Salah satunya dengan website Klinik Sehat yang membutuhkan tampilan antar muka (interface), yang mudah digunakan untuk para penggunanya. Sama dengan klinik pada umumnya, dimana ada dokter, pasien, dan apoteker. Klinik Sehat merupakan sebuah Klinik yang masih sederhana. Namun data-data pasien yang semakin banyak, sehingga tidak mungkin bila data hanya diinput ke program biasa seperti Microsoft Excel. Sehingga untuk mempermudah hubungan dokter dengan pasien, Klinik Sehat ingin membuat website yang mudah digunakan oleh semua pengguna.

Rumusan masalah pada penelitian ini yaitu akan dirancang sebuah website untuk menampilkan halaman antarmuka yang bersifat ramah (user friendly) dan sederhana sehingga memudahkan pengguna untuk mendaftarkan diri ke Klinik Sehat.

Untuk memudahkan pengguna berkontribusi pada website, maka peneliti mencoba membuat dengan menggunakan metode paper prototype. Teknik paper prototype merupakan teknik yang sangat membantu merancang sebuah aplikasi pada tahap awal pengembangannya, meskipun terlihat sederhana, teknik ini sangat berguna terutama dalam memperoleh masukan dan umpan balik dari pengguna sehingga dapat menghasilkan rancangan yang baik dan berujung pada produk akhir, dalam hal ini adalah aplikasi yang baik pula (Synder, 2003), (Aprizal dan Effendy, 2016). Manfaat yang didapat adalah meningkatkan kualitas serta memperbaiki kelemahan yang ada di website tersebut.

Beberapa penelitian mengenai pembuatan atau rancangan sebuah aplikasi dengan metode paper prototype, antara lain penelitian yang dilakukan oleh Sandhika dan Galih mengenai penggunaan metode paper prototype dengan inspeksi usability pada aplikasi berbasis web dengan studi kasus Sistem Informasi akademik Universitas. Output yang dihasilkan dari paper ini adalah sebuah paper prototype yang dijadikan acuan dalam pembuatan sistem informasi akademik dari sisi usability (Galih, dan Sandhika, 2013).

\section{TINJAUAN PUSTAKA}

\section{A. Website}

Website adalah sebuah cara untuk menampilkan diri di Internet. Dapat diibaratkan website adalah sebuah tempat di internet, siapa saja di dunia ini dapat mengunjunginya, kapan saja seseorang dapat mengetahui tentang diri orang lain, memberi pertanyaan pada seseorang, serta memberikan masukkan atau bahkan mengetahui dan membeli suatu produk (Nugraheny, 2016), (Geasela, dkk, 2018). Website (Situs Web) merupakan kumpulan dari halaman-halaman web yang berhubungan dengan file-file lain yang terkait. Dalam sebuah website terdapat suatu halaman yang dikenal dengan sebutan home page. Home page adalah sebuah halaman yang pertama kali terlihat saat membuka website. Dimana dari home page, pengunjung dapat mengklik hyperlink untuk pindah ke halaman lainnya yang terdapat pada website tersebut (Hendrianto, 2014).

\section{B. Tampilan Interface}

Interface diartikan sebagai bagian dari komputer dan software yang bisa dilihat, didengar, disentuh untuk dipahami seseorang. Interface memiliki dua komponen, yaitu: (1) komponen input, yaitu komponen yang digunakan user berinteraksi dengan komputer dan membuat user tertarik menggunakannya, (2) komponen output yaitu komponen yang menunjukkan hasil dari proses oleh user. 
Semua desain harus dimulai dengan memahami para user yang dituju, termasuk usia, jenis kelamin, kemampuan fisik, pendidikan, budaya atau latar belakang etnis, pelatihan, motivasi, tujuan dan kepribadian (Zuhro, dkk, 2014).

\section{Paper Prototype}

Teknik paper prototype merupakan teknik yang sangat membantu karena dapat digunakan pada tahap awal pengembangan perangkat lunak. Seringkali pengembang perangkat lunak mengembangkan aplikasi, baik yang berbasis web atau pun tidak itu menggunakan komponen-komponen yang ada tanpa mempertimbangkan kebutuhan dari penggunanya, dan biasanya sebagian dari pengujian yang dilakukan akan sangat terlambat dan selesai pada tahap akhir pengembangan. Faktor lain yang muncul apabila tidak menggunakan teknik ini adalah membengkaknya biaya pengembangan dan pengguna belum tentu dapat menerima produk yang dihasilkan kaena konten yang sulit dan rumit, dan lain sebagainya. Proses desain ulang sebuah aplikasi mungkin dilakukan apabila telah terjadi kasus yang sedemikian dan tentunya akan kembali memakan biaya dan waktu (Aprizal dan Effendy, 2016).

Berikut ini beberapa keuntungan dalam menggunakan teknik paper prototype:

- Lebih sedikit biaya dan sumber daya yang dibutuhkan, sumber daya dalam hal ini adalah materi dan tim yang dibutuhkan dalam membuat prototype.

- Mendapatkan kritik yang signifikan dari pengguna, yang dapat membantu meningkatkan kekurangan dari tampilan atau interface aplikasi yang akan dirancang.

- Desainer akan bersedia melakukan perubahan yang signifikan dari pengguna/user pada desain tampilan, dengan waktu dan biaya yang lebih rendah. Meningkatnya evaluasi dari pengguna aplikasi.

\section{METODE PENELITIAN}

A. Tahapan Penelitian
Metode penelitian yang dilakukan untuk menganalisa permasalahan dilakukan dalam beberapa tahapan, diperlihatkan pada Gambar 1 Tahapan Penelitian.

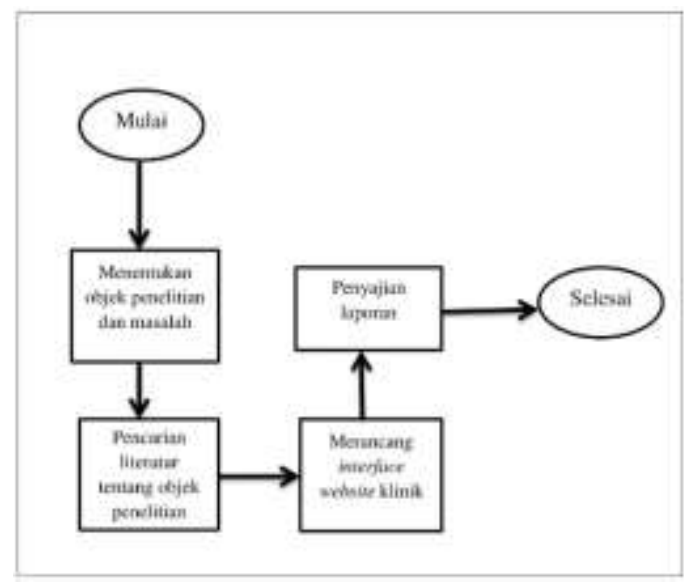

Gambar 1. Tahapan Penelitian

Menentukan objek penelitian dan masalah, Pada tahap ini, penulis menentukan objek penelitian dan masalah yang ada pada website yang ingin diteliti. Pencarian literatur tentang objek penelitian, Penulis mencari jurnal-jurnal yang berkaitan dengan penelitian ini. Data yang telah didapat dari studi ini nantinya akan digunakan sebagai acuan untuk membuat penelitian. Merancang interface website Klinik Sehat, Penulis merancang tampilan website dengan menggunakan metode paper prototype. Penyajian Laporan, Data yang telah diolah akan dibentuk menjadi sebuah laporan penelitian. Setelah itu laporan tersebut akan disusun menjadi sebuah jurnal penelitian dengan format tertentu

\section{B. Model Penelitian}

Metodologi yang digunakan adalah paper prototype. Jenis penelitian ini adalah penelitian deskriptif kualitatif, yaitu suatu metode penelitian yang dilakukan dengan tujuan utama untuk membuat gambaran atau deskripsi tentang suatu keadaan.

\section{Pengumpulan Data}

Pengumpulan data berdasarkan cara perolehannya termasuk kedalam data primer, dikarenakan peneliti langsung meneliti dari objek penelitiannya yaitu tampilan antarmuka website langsung. Berikut adalah proses yang 
dilakukan dalam melakukan pengumpulan data:

1. Menentukan objek penelitian.

2. Melakukan pengamatan terhadap tampilan antarmuka website.

3. Membuat tampilan website Klinik Sehat menggunakan wireframe. Wireframe memungkinkan seorang developer dengan mudah mengerjakan pengembangan struktur dan arah dari website atau aplikasi yang akan dibangun

\section{HASIL DAN PEMBAHASAN}

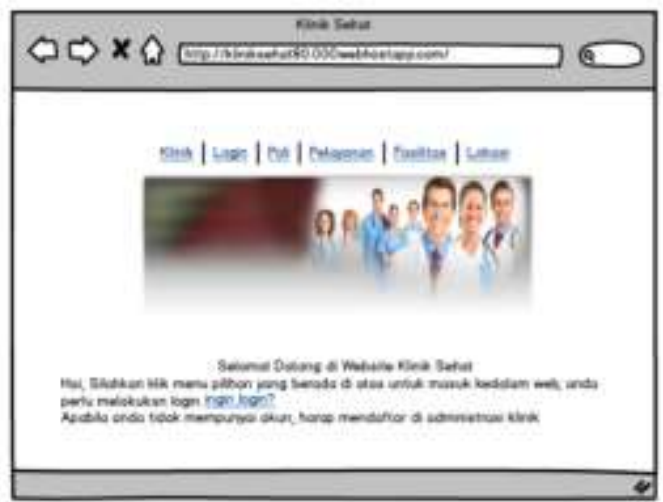

\section{Gambar 2. Index Paper Prototype}

Perancangan Paper Prototype Tampilan User Interface, penulis membuat tampilan user interface untuk website Klinik Sehat yang user friendly agar para pengguna website dapat menggunakannya dengan baik. Setelah sudah menentukan konten yang akan ditampilkan pada layout, penulis membuat dengan menggunakan wireframe.

Berikut adalah hasil perancangan paper prototype tampilan user interface dengan menggunakan wireframe pada website Klinik Sehat, bisa dilihat pada Gambar 2 Index Paper Prototype.

Penulis membuat index yang didalamnya terdapat header klinik, login, poli, pelayanan, fasilitas, dan lokasi. Header-header ini berfungsi untuk menampilkan informasi kepada pengguna. Index merupakan sebuah halaman utama pada sebuah web. Jika kita memasukan url, secara otomatis akan dilempar ke halaman index terlebih dahulu. Sehingga halaman index membutuhkan design yang cukup menarik untuk para user agar website tersebut memiliki halaman index yang cukup menarik untuk dilihat.

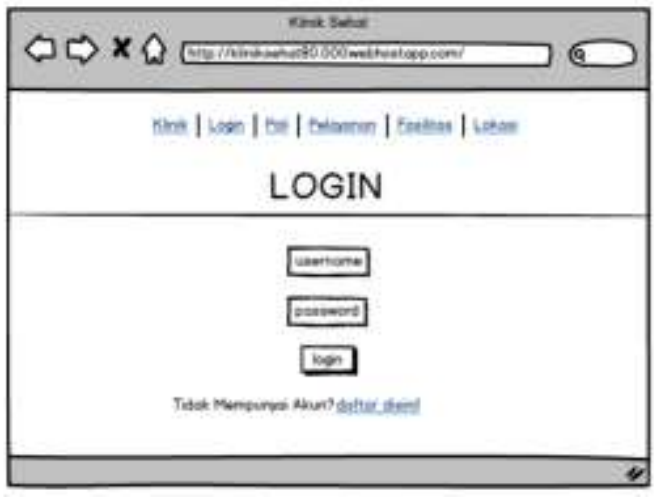

Gambar 3. Login

Halaman login, pada Gambar 3. Login, diperuntukkan bagi para pengguna dan admin. Login berisi username dan password untuk mengakses data masing-masing bagi pengguna dan data pengguna bagi admin Klinik Sehat. Login disebut juga logon atau sign in adalah istilah dalam hal keamanan komputer, yakni berupa proses pintu masuk bagi pengguna untuk mengakses sistem komputer. Login dimaksudkan untuk mengatur proses identifikasi. Dengan login, user akan diketahui admin identitasnya dan memudahkan admin untuk mengetahui user mana yang telah mendaftar ke bagian tertentu.

Poli menurut kamus besar bahasa Indonesia artinya adalah bentuk terikat. Istilah poli menerangkan sebuah bentuk yang banyak yang terikat dalam suatu kesatuan. Pada halaman poli, bisa dilihat pada Gambar 4. Poli, bagian bawah halaman ini terdapat jadwal hari jenis-jenis poli yang ada pada klinik tersebut. Bagian atas halaman poli terdapat gambar berupa dokter-dokter dan beberapa menu pilihan yang bisa diklik dan kehalaman yang kita pilih. Bagian kanan halaman poli, terdapat jam buka dan contact person klinik tersebut. 


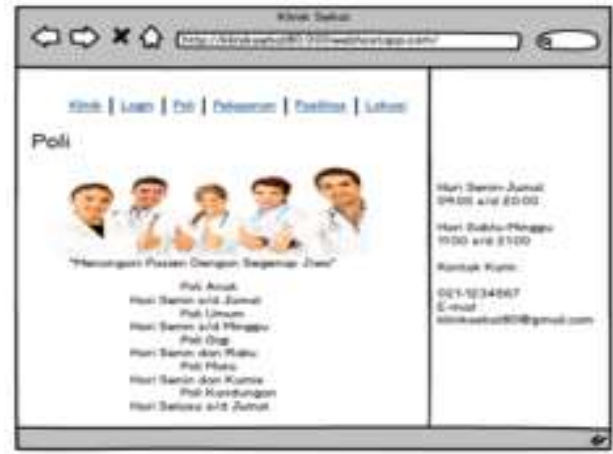

\section{Gambar 4. Poli}

Halaman pelayanan bisa di lihat pada Gambar 5. Pelayanan berisi informasi pelayanan-pelayanan apa saja yang bisa diberikan kepada pasien. Pada halaman pelayanan, ada beberapa gambar yang diberikan kepada pengunjung, yaitu gambar dari pelayanan yang ada pada klinik tersebut.

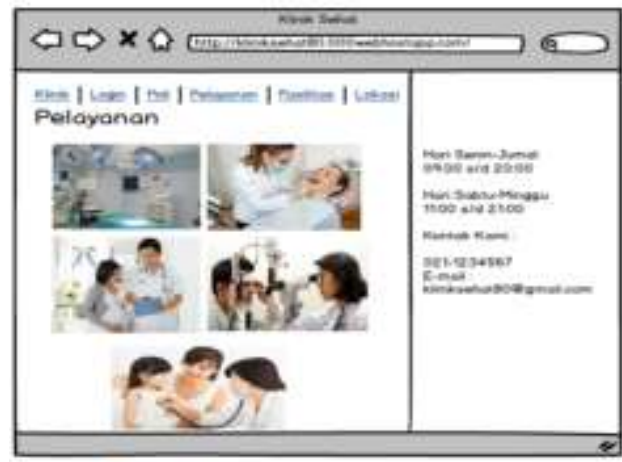

Gambar 5. Pelayanan

Pada gambar pertama, ada gambar dari ruangan laboratorium pada klinik tersebut, gambar kedua merupakan dokter gigi, dan selanjutnya ada dokter kandungan, dokter mata, dan dokter anak.

Halaman fasilitas pada Gambar 6 disampiakan, Klinik Sehat berisi sarana apa saja yang diberikan klinik sehat kepada pasien.

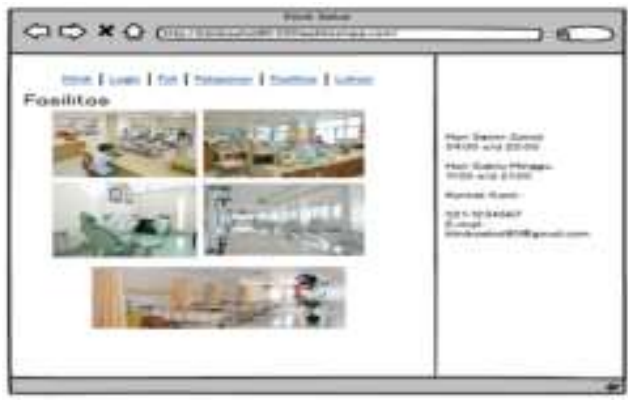

Gambar 6. Fasilitas
Pada halaman ini, klinik sehat memberikan beberapa gambaran tentang fasilitas yang dimiliki. Fasilitas tersebut berupa ruang tunggu yang nyaman, ruang inap, laboratorium, ruangan dokter gigi, kantor yang dimiliki oleh klinik tersebut. Pada halaman ini, klinik sehat ingin memperlihatkan fasilitas yang dimiliki klinik tersebut.

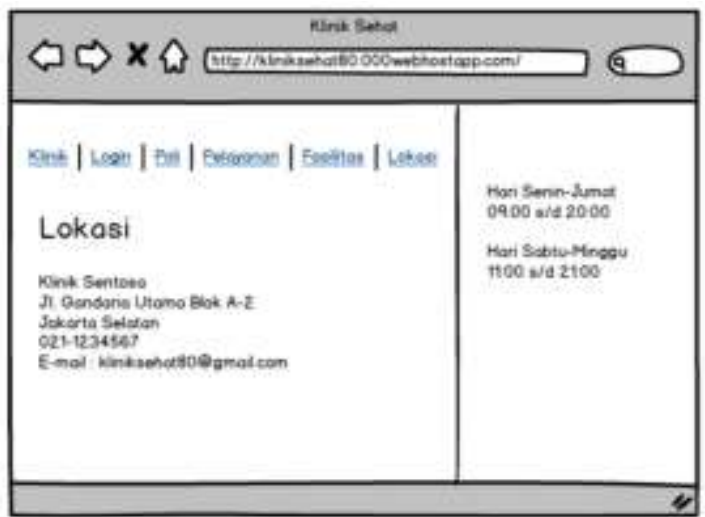

Gambar 7. Paper Prototype Lokasi

Halaman lokasi pada Gambar 7. Paper Prototype Lokasi berisi informasi lokasi Klinik Sehat. Klinik sehat berlokasi pada Jl. Gandaria Utama Blok A-2 Jakarta selatan. Halaman ini diperuntukan kepada pengguna yang ingin mencari letak klinik tersebut, diberikan pula nomor dan email agar pengguna mudah untuk menghubungi pihak klinik.

Pada Gambar 8. Paper Prototype Registrasi, halaman registrasi ini diperuntukkan bagi yang belum mempunyai akun pada website Klinik Sehat. Tujuan dari registrasi ini adalah untuk admin mengetahui identitas user. Dengan mengetahui identitas user, admin akan dengan mudah mendaftarkan diri user ke bagian yang diinginkan, misalkan ke bagian pelayanan, dll. Registrasi juga ditujukan agar identitas user jelas. 


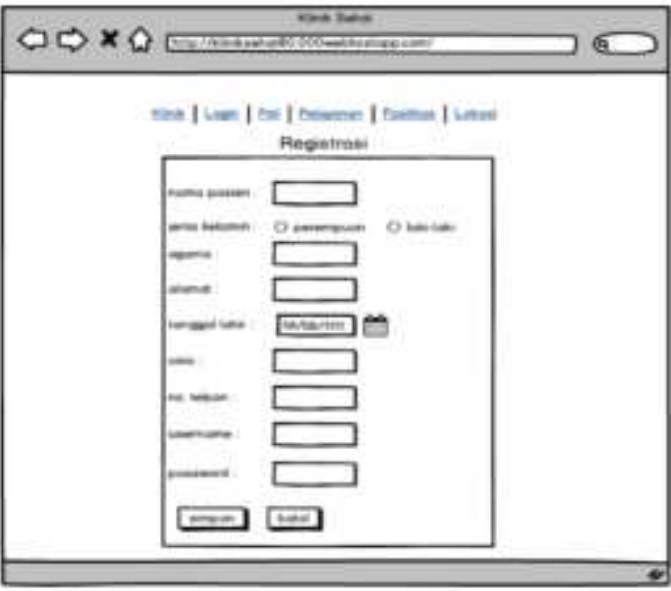

Gambar 8. Paper Prototype Registrasi

\section{KESIMPULAN DAN SARAN}

Dari hasil analisis dan pembahasan yang telah diuraikan di atas, maka dapat disimpulkan bahwa:

- Metode paper prototype cocok digunakan untuk membuat tampilan user interface pada website seperti Klinik Sehat.

- Metode paper prototype juga dapat membuat tampilan user interface yang user friendly bagi para pengguna website.

- Pengguna dapat melakukan ujicoba antarmuka dengan aksi-aksi yang nyata.

- Dapat menentukan sendiri aksi atau tugas apa saja yang bisa dipahami dan dilakukan ketika menggunakan aplikasi/website tersebut secara intuitif.

Saran pada penelitian selanjutnya akan dilakukan implementasi terhadap Klinik Sehat dengan menggunakan bahasa pemrograman tertentu, Untuk pengembangan selanjutnya agar website ini dapat lebih memaksimalkan keamanan sistem yang ada dan Proses pembayaran dapat dilakukan di website tersebut secara online.

\section{DAFTAR PUSTAKA}

Andry, J. F., Deny., Yonathan, O. (2020). Profesi Teknologi Informasi Dalam Industri E-Commerce Di Indonesia, Jurnal Pengabdian dan Kewirausahaan Vol. 4, No. 1. hal 1 - 9.

Alfian, N., Sri Kusumadewi, dan Kariyam. (2014). Analisis Pengaruh User Interface Terhadap Kemudahan Penggunaan
Sistem Pendukung Keputusan Seorang Dokter. Yogyakarta: Prosiding SNATIF Ke-1.

Awais, M., dan Samin, T. (2012). Advanced SWOT Analysis of E-Commerce," International Journal of Computer Science, vol. 9, issue 2, no. 2, pp. 569574.

Aprizal, Y. dan Effendi, B. (2016). Penerapan Metode Paper Prototype Dalam Pembuatan Interface Aplikasi Pemutar Musik. Seminar Nasional Teknologi Informasi, Bisnis, dan Desain.

Geasela, Y. M., Ranting, P., dan Andry, J. F. (2018). Analisis User Interface terhadap Website Berbasis E-Learning dengan Metode Heuristic Evaluation, Jurnal Informatika, Vol.5 No.2 September 2018, hal. 270-277.

Hendrianto, D. E. (2014). Pembuatan Sistem Informasi Perpustakaan Berbasis Website Pada Sekolah Menengah Pertama Negeri 1 Donorojo Kabupaten Pacitan. Indonesian Journal on Networking and Security, Volume 3, No 4. 2014.

Nugraheny, D. (2016). Analisis User Interface dan User Experience pada Website Sekolah Tinggi Teknologi Adisutjipto Yogyakarta. SENATIK, 2.

Galih, R., Sandhika. (2013). Penggunaan Metode Paper Prototype untuk Melakukan Inspeksi Usability pada Aplikasi Berbasis Web (Studi Kasus : Sistem Informasi Akademik Universitas. Jurnal SeTISI.

Snyder., C. (2003). Paper Prototyping : The Fast And Easy Way to Design And Refine User Interfaces. San Francisco, CA : Morgan Kaufmann.

Zuhroh, E. S, Astuti dan Riyadi. (2014). Pengaruh Karakteristik Interface Terhadap Penggunaan Sistem Informasi Perpustakaan Digital(Studi pada Pengguna (Mahasiswa) Perpustakaan Digital Universitas Brawijaya Malang. Malang : Jurnal Administrasi Bisnis (JAB). Vol. 11 No. 1. 